\title{
Avaliação da qualidade microbiológica de bebida láctea e creme de leite UAT por ATP-Bioluminescência
}

\author{
[Evaluation of microbiological quality of UHT milk drink and UHT milk \\ cream by ATP-Bioluminescence] \\ A.F. Cunha ${ }^{1}$, A.D. Lage ${ }^{1}$, M.M. Pereira e Araújo ${ }^{1}$, R.D.P. Santos ${ }^{2}$, \\ G.M. Resende ${ }^{2}$, M.M.O.P. Cerqueira ${ }^{3}$ \\ ${ }^{1}$ Alunos de pós-graduação - Universidade Federal de Minas Gerais - Belo Horizonte, MG \\ ${ }^{2}$ Aluna de graduação - Universidade Federal de Minas Gerais - Belo Horizonte, MG \\ ${ }^{3}$ Universidade Federal de Minas Gerais - Belo Horizonte, MG
}

\begin{abstract}
RESUMO
Embora métodos tradicionais sejam utilizados na avaliação microbiológica de produtos UAT, metodologias rápidas, baseadas em ATP-Bioluminescência, têm sido desenvolvidas. Os resultados da aplicação dessa técnica em 54 amostras de bebida láctea UAT achocolatada e 12 de creme de leite UAT foram comparados com os resultados de métodos microbiológicos, utilizando-se diferentes meios de cultura e tempos de incubação das referidas amostras. A técnica de ATP-Bioluminescência foi aplicada por meio do sistema MLS, e os resultados foram expressos em unidades relativas de luz (RLU). Em todos os tempos de incubação - 48, 72 e 168 horas -, as amostras apresentaram contagens baixas de microrganismos mesófilos e psicrotróficos aeróbios quando analisadas em meio PCA, BHI, Petrifilm ${ }^{\mathrm{TM}} \mathrm{AC}$ e por ATP-Bioluminescência $(<150 \mathrm{RLU})$, demonstrando alta especificidade da técnica. Apenas uma amostra de creme de leite UAT apresentou contagem de mesófilos aeróbios acima do padrão estabelecido pela legislação brasileira $(<100 \mathrm{UFC} / \mathrm{mL})$ quando analisada em meio PCA $(260 \mathrm{UFC} / \mathrm{mL})$ e Petrifilm ${ }^{\mathrm{TM}} \mathrm{AC}(108 \mathrm{UFC} / \mathrm{mL})$, no tempo de 168 horas. Essa alta contagem de microrganismos mesófilos aeróbios também foi detectada pela técnica de ATP-Bioluminescência (416 RLU). Os resultados da técnica de ATP-Bioluminescência foram iguais aos resultados em meio PCA, BHI e Petrifilm ${ }^{\mathrm{TM}} \mathrm{AC}$.
\end{abstract}

Palavras-chave: UAT, ATP-Bioluminescência, Petrifilm ${ }^{\mathrm{TM}}$ AC, PCA, BHI

\begin{abstract}
Although traditional methods are used for the microbiological evaluation of UHT products, rapid methodologies based on ATP-Bioluminescence have been developed. The results of applying this technique in 54 samples of chocolate UHT milk drink and 12 of UHT milk cream were compared with the results of microbiological methods, using different culture media and incubation times for the referred samples. The ATP-Bioluminescence technique was applied through the MLS system and the results were expressed as relative light units (RLU). In all incubation times $-48,72$, and 168 hours -, the samples showed lower counts of mesophilic and psychrotrophic aerobic microorganisms when analyzed using PCA, BHI, Petrifilm ${ }^{T M} A C$ and ATP-Bioluminescence $(<150 R L U)$, demonstrating the technique's high specificity. Only one sample of UHT milk cream showed a mesophilic aerobic count above the standard established by Brazilian legislation $(<100 C F U / m L)$ when analyzed in PCA $(260 \mathrm{CFU} / \mathrm{mL})$ and Petrifilm ${ }^{T M}$ AC (108CFU/mL) at 168 hours. This high count of aerobic mesophilic microorganisms was also detected by the ATP-Bioluminescence (416 RLU) technique. The results of the ATP-Bioluminescence technique were equal to the results in PCA, BHI and Petrifilm ${ }^{T M} A C$.
\end{abstract}

Keywords: UHT, ATP-Bioluminescence, Petrifilm ${ }^{T M}$ AC, PCA, BHI

Recebido em 26 de agosto de 2011

Aceito em 1 de outubro de 2012

E-mail: adrianofcunha@yahoo.com.br 


\section{INTRODUÇÃO}

Atualmente no Brasil, o tratamento térmico ultra alta temperatura (UAT) é amplamente utilizado pelas indústrias alimentícias. Os produtos lácteos UAT, entre eles a bebida láctea achocolatada e o creme de leite, caracterizam-se por elevada vida de prateleira e pelas facilidades que oferecem aos consumidores. Apesar da crescente demanda desses derivados lácteos, a avaliação da qualidade desses produtos é pouco evidenciada na literatura científica. A qualidade microbiológica destes pode limitar a conquista de mercados, tornando imprescindível seu monitoramento. Após o tratamento UAT, formas esporuladas de alguns microrganismos altamente resistentes ao calor podem estar presentes no produto, tornando-o impróprio conforme a legislação brasileira. Além disso, esses microrganismos podem alterar as características do produto, diminuindo sua vida de prateleira e, ainda, comprometer a saúde do consumidor.

Existem vários métodos disponíveis para detecção e enumeração de microrganismos em derivados lácteos. Alguns são rotineiramente utilizados em laboratório e são referenciados por instituições de pesquisa e pelos próprios órgãos de inspeção. No entanto, as metodologias tradicionais disponíveis para avaliação da qualidade dos produtos UAT são demoradas e trabalhosas, o que dificulta a implantação rápida de ações corretivas pelas indústrias e órgãos de inspeção.

Considerando esses aspectos, metodologias rápidas, baseadas em ATP-Bioluminescência, têm sido desenvolvidas, mas a literatura científica sobre a aplicação dessa técnica em produtos UAT é escassa. Tal técnica baseia-se na concentração de ATP (adenosina trifosfato) microbiano encontrado na amostra, o qual reage com um complexo enzima-substrato chamado de luciferina-luciferase. A reação formada libera um tipo de luz, e sua intensidade é mensurada por luminômetros em unidades relativas de luz (RLU). Portanto, a alta intensidade de luz está relacionada com elevada contagem microbiana em uma amostra de produto lácteo (Corbitt et al., 2000; Costa et al., 2004; Pires et al., 2005; Costa et al., 2006; Whitehead et al., 2008).

A produção de luz requer uma reação inicial, em que o substrato luciferina na presença de ATP e $\mathrm{Mg}^{2+}$ é convertido em luciferil adenilato pela enzima luciferase, liberando pirofosfato livre (PPi). O intermediário luciferil adenilato, ainda em catálise enzimática, combina-se com o oxigênio molecular (descarboxilação oxidativa) para se transformarem no complexo oxiluciferiladenilato-enzima, eletronicamente excitado. No retorno ao estado mais baixo de excitação, o complexo dissocia-se para formar a enzima luciferase, AMP (monofosfato de adenosina), dióxido de carbono $\left(\mathrm{CO}_{2}\right)$, oxiluciferina e consequente emissão de fótons de luz (Griffiths, 1993; Santos et al., 1993).

Dada a importância de se estabelecer novos indicadores de qualidade e identificar mais rapidamente possíveis contaminações, este trabalho objetivou avaliar a qualidade microbiológica de bebidas lácteas UAT achocolatadas e cremes de leite UAT utilizando diferentes métodos microbiológicos, meios de cultura, tempos de incubação, comparando-a com os resultados obtidos pela técnica de ATP-Bioluminescência.

\section{MATERIAL E MÉTODOS}

No período de novembro de 2009 a março de 2010, 66 amostras - 54 de bebida láctea UAT achocolatada e 12 de creme de leite UAT foram coletadas em indústrias de laticínios e encaminhadas rapidamente ao laboratório de microbiologia de alimentos, onde foram incubadas em estufa a $36 \pm 1^{\circ} \mathrm{C}$ por 48,72 e 168 horas, correspondendo a 22 amostras por tempo de incubação. Em seguida, as amostras foram analisadas em duplicata.

As análises microbiológicas foram realizadas pelo método de contagem padrão em placa (Ágar Padrão - Oxoid, England), segundo a Instrução Normativa $n^{\circ} 62$ (Brasil, 2003), e em placas Petrifilm $^{\mathrm{TM}}$ Aerobic Count (Petrifilm ${ }^{\mathrm{TM}} \mathrm{AC}$ ), segundo recomendações do fabricante (3M, 1997), para enumeração de microrganismos mesófilos aeróbios $\left(36 \pm 1^{\circ} \mathrm{C} / 48\right.$ horas $)$, segundo APHA (1992), e de psicrotróficos aeróbios $\left(21 \pm 1^{\circ} \mathrm{C} / 25\right.$ horas), segundo IDF (1991). As amostras ainda foram analisadas em meio BHI (Brain Heart Infusion - Oxoid, England) pela técnica de spread plate, para enumeração de microrganismos mesófilos aeróbios $\left(36 \pm 1^{\circ} \mathrm{C} / 48\right.$ horas). Os meios PCA e BHI foram adicionados do corante indicador cloreto de 2,3,5trifeniltetrazólio $(0,5 \%$ v/v) em concentração de 
$1,0 \%$, para facilitar a visualização das colônias. Os resultados foram expressos em $\mathrm{UFC} / \mathrm{mL}$ do produto.

As mesmas amostras foram ainda submetidas à análise por ATP-Bioluminescência em equipamento eletrônico $3 \mathrm{M} \quad$ Microbial Luminescence System (MLS), conforme recomendação do fabricante (3M, s.d). Primeiramente, uma limpeza das tubulações do equipamento foi realizada utilizando água livre de ATP e solução de limpeza específica. Em seguida, um ensaio de verificação dos reagentes ATPase, extratante e luciferina-luciferase 1 (L/L1) foi realizado por meio de ATP controle. A ATPase era adicionada automaticamente às amostras de produto UAT, com a função de degradar o ATP livre; o extratante para romper a célula microbiana intacta, liberando o ATP microbiano; e a L/L1 para criar uma reação entre o L/L1 e o ATP microbiano, resultando em emissão de luz bioluminescente (3M, s.d.).

Após verificar a atividade dos reagentes, $50 \mu \mathrm{L}$ de cada amostra dos produtos lácteos foram pipetados e transferidos para micropoços inseridos em placa de ensaio para que esta fosse acoplada ao equipamento, iniciando-se a análise eletrônica. Após a realização das análises, foi feita a leitura em RLU. Amostras com valores inferiores a 150 RLU foram consideradas aprovadas quanto à qualidade microbiológica, de acordo com o fabricante (3M, s.d.). Submeteramse todos os resultados à análise estatística descritiva de acordo com Sampaio (2002).

\section{RESULTADOS E DISCUSSÃO}

Em todos os tempos de incubação, as amostras de bebida láctea UAT achocolatada apresentaram contagens muito baixas de microrganismos mesófilos e psicrotróficos aeróbios (Tab. 1), quando analisadas em meio PCA, BHI, placas Petrifilm ${ }^{\mathrm{TM}}$ AC e de ATP em equipamento MLS. Esse fato pode ser comprovado pelas contagens máximas e mínimas (amplitude) observadas em todos os métodos e tempos avaliados. Todas as amostras analisadas, inclusive quando incubadas a 168 horas, tempo de incubação preconizado pela legislação, apresentaram contagens bacterianas dentro dos padrões estabelecidos pela legislação brasileira (Brasil, 2005), ou seja, abaixo de $100 \mathrm{UFC} / \mathrm{mL}$. Além disso, todas as amostras apresentaram contagens abaixo de 150 RLU, valor estabelecido pelo fabricante (3M, s.d.) e foram consideradas aprovadas pelo equipamento MLS $(100 \%$ de amostras negativas).

Tabela 1. Variação das contagens bacterianas (UFC/mL) e resultados de ATP-Bioluminescência (RLU) e número de amostras positivas e negativas das bebidas lácteas UAT achocolatadas de acordo com os valores de referência

\begin{tabular}{|c|c|c|c|c|c|c|c|c|c|}
\hline \multirow[b]{2}{*}{ Análise microbiológica/Método } & \multicolumn{3}{|c|}{48 horas } & \multicolumn{3}{|c|}{72 horas } & \multicolumn{3}{|c|}{168 horas } \\
\hline & $\begin{array}{l}\text { Mínimo } \\
\text { Máximo }\end{array}$ & Neg. & Pos. & $\begin{array}{l}\text { Mínimo } \\
\text { Máximo }\end{array}$ & Neg. & Pos. & $\begin{array}{l}\text { Mínimo } \\
\text { Máximo }\end{array}$ & Neg. & Pos. \\
\hline Mesófilos/PCA* & $0-0$ & 18 & 0 & $0-15$ & 18 & 0 & $1-15$ & 18 & 0 \\
\hline Mesófilos /Petrifilm ${ }^{\mathrm{TM}} \mathrm{AC}^{*}$ & $0-5$ & 18 & 0 & $0-4$ & 18 & 0 & $0-0$ & 18 & 0 \\
\hline Psicrotróficos/PCA* & $0-0$ & 18 & 0 & $0-2$ & 18 & 0 & $0-1$ & 18 & 0 \\
\hline Psicrotróficos/Petrifilm ${ }^{\mathrm{TM}} \mathrm{AC}^{*}$ & $0-0$ & 18 & 0 & $0-0$ & 18 & 0 & $0-1$ & 18 & 0 \\
\hline Mesófilos/BHI* & $0-20$ & 18 & 0 & $0-15$ & 18 & 0 & $0-90$ & 18 & 0 \\
\hline ATP-Bioluminescência/MLS** & $15-35$ & 18 & 0 & $15-43$ & 18 & 0 & $20-44$ & 18 & 0 \\
\hline
\end{tabular}

*Limite de referência de $100 \mathrm{UFC} / \mathrm{mL}$.

**Limite de referência de 150 RLU de acordo com o fabricante.

As contagens de mesófilos e psicrotróficos aeróbios e de ATP, em amostras de creme de leite UAT, em todos os métodos e tempos de incubação, também foram baixas em praticamente todas as amostras (Tab. 2). Além disso, quase $100 \%$ das amostras apresentaram resultados dentro dos padrões estabelecidos pela legislação (Brasil, 1996). Apenas uma amostra apresentou contagens de mesófilos aeróbios não conforme quando analisada em meio PCA (260 $\mathrm{UFC} / \mathrm{mL}$ ) e Petrifilm ${ }^{\mathrm{TM}}$ AC (108 UFC/mL), no tempo de 168 horas. A técnica de ATPBioluminescência, princípio do equipamento MLS, foi capaz de detectar a alta contagem de microrganismos mesófilos aeróbios dessa amostra, pela mensuração de ATP microbiano (416 RLU). 
Tabela 2. Variação das contagens bacterianas (UFC/mL) e resultados de ATP-Bioluminescência (RLU) e número de amostras positivas e negativas dos cremes de leite UAT de acordo com os valores de referência

\begin{tabular}{|c|c|c|c|c|c|c|c|c|c|}
\hline \multirow{2}{*}{$\begin{array}{c}\text { Análise } \\
\text { microbiológica/Método }\end{array}$} & \multicolumn{3}{|c|}{48 horas } & \multicolumn{3}{|c|}{72 horas } & \multicolumn{3}{|c|}{168 horas } \\
\hline & $\begin{array}{l}\text { Mínimo } \\
\text { Máximo }\end{array}$ & Neg. & Pos. & $\begin{array}{l}\text { Mínimo } \\
\text { Máximo }\end{array}$ & Neg. & Pos. & $\begin{array}{l}\text { Mínimo } \\
\text { Máximo }\end{array}$ & Neg. & Pos. \\
\hline Mesófilos/PCA* & $0-15$ & 4 & 0 & $0-10$ & 4 & 0 & $0-260$ & 3 & 1 \\
\hline Mesófilos /Petrifilm ${ }^{\mathrm{TM}} \mathrm{AC}^{*}$ & $0-0$ & 4 & 0 & $0-0$ & 4 & 0 & $0-108$ & 3 & 1 \\
\hline Psicrotróficos/PCA* & $0-0$ & 4 & 0 & $0-0$ & 4 & 0 & $0-0$ & 4 & 0 \\
\hline $\begin{array}{l}\text { Psicrotróficos/Petrifilm }{ }^{\mathrm{TM}} \\
\mathrm{AC}^{*}\end{array}$ & $0-0$ & 4 & 0 & $0-0$ & 4 & 0 & $0-0$ & 4 & 0 \\
\hline Mesófilos/BHI* & $0-1$ & 4 & 0 & $0-10$ & 4 & 0 & $0-25$ & 4 & 0 \\
\hline $\begin{array}{l}\text { ATP- } \\
\text { Bioluminescência/MLS** }\end{array}$ & $24-30$ & 4 & 0 & $19-25$ & 4 & 0 & $23-416$ & 3 & 1 \\
\hline
\end{tabular}

*Limite de referência de $100 \mathrm{UFC} / \mathrm{mL}$

**Limite de referência de 150 RLU de acordo com o fabricante.

Considerando as 22 amostras de produtos UAT incubadas por 168 horas (Tab. 1 e 2), 95,5\% das amostras apresentaram contagens de microrganismos mesófilos em conformidade com as respectivas legislações dos produtos (Brasil, 1996; Brasil, 2005). No entanto, a detecção da amostra de creme de leite UAT acima do limite padrão sugere a necessidade de melhorias das condições higiênico-sanitárias em todo o fluxograma de processamento e armazenamento do produto.

Os resultados obtidos demonstram alta especificidade da técnica ATPBioluminescência, pois o equipamento MLS foi capaz de mensurar corretamente baixas contagens de ATP e considerar aprovadas as amostras que realmente estavam em conformidade com a legislação brasileira e que apresentaram baixas contagens de microrganismos aeróbios nos métodos de referência.

Alguns estudos de ATP-Bioluminescência disponíveis na literatura não utilizam equipamentos que diferenciam o ATP microbiano do ATP de origem não microbiana, ou seja, consideram as bactérias como os únicos, ou pelo menos dominantes, microrganismos presentes. Os sistemas biológicos possuem outras fontes não bacterianas de $\operatorname{ATP} e$, consequentemente, o ATP microbiano representa apenas uma porção responsável pela bioluminescência. A interferência de ATP de origem não microbiana pode limitar a sensibilidade do método e a ocorrência de falsos positivos (Siragusa et al., 1995; Akutsu, 2001;
Costa, 2001; Vilar et al., 2008). Talvez por essa razão discrepâncias ocorram entre os resultados dessa técnica e os resultados de contagem de microrganismos em placas.

Para contornar esse problema, avanços foram realizados com relação à instrumentação, reagentes e inclusão de métodos de filtração bacteriana (Rocha, 2007). Luo et al. (2009) avaliaram um biosensor baseado em ATPBiolumenescência, que consiste de um classificador com um cartucho onde o ATP intracelular é extraído quimicamente da bactéria para reagir com o reagente luciferina-luciferase. Fatores que afetam a quantidade de ATP extraído, incluindo os tipos e a concentração de extratantes de ATP, foram eliminados. Os resultados da técnica de ATP-Bioluminescência apresentaram resposta linear com a contagem padrão em uma faixa de 103 a $108 \mathrm{UFC} / \mathrm{mL}$ de uma variedade de alimentos, com coeficiente de correlação de 0,925 . Os autores concluíram que o biosensor permite avaliação rápida da contaminação bacteriana na indústria de alimentos, monitoramento ambiental e outros campos.

Neste trabalho, o sistema MLS baseou-se na utilização prévia de reagentes específicos, como a ATPase, que degrada o ATP não microbiano e o extratante que rompe as células microbianas intactas, liberando ATP microbiano. Portanto, apenas o ATP microbiano participa da reação de bioluminescência e, consequentemente, apenas ele é determinado pelo luminômetro. Esse fato contribuiu para explicar a capacidade de o sistema MLS detectar corretamente as baixas 
contagens de microrganismos mesófilos nas amostras analisadas.

Em termos de praticidade, a técnica de quantificação de ATP por bioluminescência mostrou-se de grande valia em virtude da facilidade e rapidez de execução (40 minutos para cada 96 amostras). A técnica de preparo prévio de vidrarias e meios de culturas, necessária nas metodologias convencionais, não precisa ser realizada quando se utiliza o equipamento MLS. Além disso, os resultados foram facilmente obtidos e interpretados devido à automatização do método.

\section{CONCLUSÕES}

A maioria das amostras de bebida láctea UAT achocolatada e de creme de leite UAT estava dentro dos padrões estabelecidos pelas suas respectivas legislações (Brasil, 2005; Brasil, 1996) quando avaliadas por meios e em tempos de incubação diferentes. Além disso, os resultados da técnica de ATP-Bioluminescência foram coerentes com a contagem bacteriana em meio PCA, BHI e em placas Petrifilm ${ }^{\mathrm{TM}} \mathrm{AC}$, demonstrando alta especificidade do equipamento MLS.

\section{REFERÊNCIAS}

3M do Brasil Ltda. Petrifilm placa para contagem de aeróbios. folheto de instrução de uso. USA, 1997.

3M do Brasil Ltda. Sistema de Luminescência Microbiana (MLS) 3M. manual do usuário do instrumento MLS-USB, s.d.

AKUTSU, C.K. Adesão de esporos de Bacillus sporothermodurans ao aço inoxidável e sua resistência a sanificantes químicos em condições de uso simulado. 2001. 84f. Dissertação (Mestrado em Ciência e Tecnologia de Alimentos) - Universidade Federal de Viçosa, Viçosa, MG.

BRASIL. Ministério da Agricultura, Pecuária e Abastecimento. Portaria $\mathrm{N}^{\mathrm{o}} 146$ de 07 de março de 1996. Regulamento Técnico de Identidade e Qualidade de Creme de Leite. Diário Oficial da União, Brasília, 11 de março de 1996.
BRASIL. Ministério da Agricultura, Pecuária e Abastecimento. Instrução Normativa $\mathrm{N}^{\circ}$ 62, de 26 de agosto de 2003. Métodos analíticos oficiais para análises microbiológicas para controle de produtos de origem animal e água. Diário Oficial da União, Brasília, 18 de setembro de 2003.

BRASIL. Ministério da Agricultura, Pecuária e Abastecimento. Instrução Normativa $\mathrm{N}^{\circ} 16$, de 23 de agosto de 2005. Regulamento Técnico de Identidade e Qualidade de Bebida Láctea. Diário Oficial da União, Brasília, 24 de agosto de 2005.

CORBITT, A.J.; BENNION, N.; FORSYTHE, S.J. Adenylate kinase amplification of ATP bioluminescence for hygiene monitoring in the food and beverage industry. Lett. Appl. Microbiol., v.30, p.443-447, 2000.

COSTA, P.D. Avaliação da técnica de ATPbioluminescência no controle do procedimento de higienização na indústria de laticínios. 2001. 79f. Dissertação (Mestrado em Ciência e Tecnologia de Alimentos) - Universidade Federal de Viçosa, Viçosa, MG.

COSTA, P.D.; ANDRADE, N.J.; BRANDÃO, S.C.C. et al. ATP-bioluminescence assay as an alternative for hygiene-monitoring procedures of stainless steel milk contact surfaces. Braz. J. Microbiol., v.37, p.345-349, 2006.

COSTA, P.D.; ANDRADE, N.J.; PASSOS, F.J.V. et al. ATP-Bioluminescence as a technique to evaluate the microbiological quality of water in food industry. Braz. Arch. Biol. Tech., v.47, p.399-405, 2004.

GRIFFITHS, M.W. Applications of bioluminescence in the dairy industry. J. Dairy Sci., v.76, p.3118-3125, 1993.

IDF Standard 132 A: 1991 - Milk - estimation of numbers of psychrotrophic microorganisms rapid colony count technique 25 hours at $21^{\circ} \mathrm{C}$.

LUO, J.; LIU, X.; TIAN, Q. et al. Disposable bioluminescence-based biosensor for detection of bacterial count in food. References and further reading may be available for this article. To view references and further reading you must purchase this article. Anal. Bioch., v.394, p.1-6, 2009. 
PIRES, A.C.S.; ARAÚJO, E.A.; CAMILLOTO, G.P. et al. Condições higiênicas de fatiadores de frios avaliadas por ATP-bioluminescência e contagem microbiana: sugestão de higienização conforme RDC 275 da ANVISA. Alim. Nutr., v.16, p.123-129, 2005.

ROCHA, V.S. Determinação de carbono orgânico assimilável em amostras de água. 2007. 108f. Dissertação (Mestrado em Engenharia Biológica) - Instituto Superior Técnico, Universidade Técnica de Lisboa, Lisboa.

SAMPAIO, I.B.M. Estatística aplicada a experimentação animal. 2.ed. Belo Horizonte: Fundação de Ensino e Pesquisa em Medicina Veterinária e Zootecnia, 2002. 265p.

SANTOS, R.M.S.; SANTOS, M.F.; COSTA, M.F.D. Revisão: quimioluminescência e bioluminescência. Quím. Nova, v.16, p.200-209, 1993.
SIRAGUSA, G.R.; CUTTER, C.N.; DORSA, W.J. et al. Use of rapid microbial ATP bioluminescence assay to detect contamination on beef and pork carcasses. J. Food Prot., v.58, p.770-775, 1995.

VILAR, M.J.; RODRÍGUEZ-OTERO, J.L.; DIÉGUEZ, F.J. et al. Application of ATP bioluminescence for evaluation of surface cleanliness of milking equipment. Int. J. Food Microbiol., v.125, p.357-361, 2008.

WHITEHEAD, K.A.; SMITH, L.A.; VERRAN, J. The detection of food soils and cells on stainless steel using industrial methods: UV illumination and ATP bioluminescence. Int. J. Food Microbiol., v.127, p.121-128, 2008. 